\title{
Experiências e reflexões sobre a prática docente Anti/Contra/Decolonial no ensino da História na escola pública e suas relações com o Museu da Maré como uma ferramenta pedagógica da Educação Popular
}

\author{
Experiences and reflections on the Anti/Contra/Decolonial teaching practice in the \\ teaching of History in public schools and its relations with the Museum of Maré as a \\ pedagogical tool of Popular Education
}

Noélia Rodrigues Pereira Rego
Educadora Popular
Doutora em Educação pela Universidade Federal do Estado do Rio de Janeiro - UNIRIO
noeliarpr@gmail.com

Humberto Salustriano da Silva

Educador Popular

Doutor em Educação pela Universidade Federal do Estado do Rio de Janeiro - UNIRIO

Pesquisador NEPS-CEASM

humbertosalustriano@gmail.com

\begin{abstract}
Francisco Overlande Manço de Souza
Educador Popular

Professor de História da rede pública de ensino do Estado do Rio de Janeiro (SEEDUC-RJ) Mestrando do programa de Pós-Graduação em Educação, Cultura e Comunicação em Periferias Urbanas da Universidade do Estado do Rio de Janeiro (UERJ-FEBF)

Pesquisador NEPS-CEASM

franciscooverlande@gmail.com
\end{abstract}

Resumo: O artigo trata da experiência de prática docente decolonial em turmas do ensino médio em escolas da rede pública do estado do Rio de Janeiro tendo como proposta pedagógica a utilização do Museu da Maré como exemplo de pedagogia Anti/Contra/Decolonial que pode ser usada em sala de aula como forma de contrapor uma historiografia tradicional eurocentrada. A experiência museológica e epistemológica do Museu da Maré nos oferece subsídios didáticos para uma historiografia alinhada aos grupos subalternizados, quando utiliza em suas práticas elementos da Educação Popular, alinhados ao da Anti/Contra/Decolonialidade.

\section{Palavras-chave:}

Anti/Contra/Decolonialidade; Ensino de História; Museu da Maré.

\begin{abstract}
The article deals with the experience of decolonial teaching practice in high school classes in public schools in the state of Rio de Janeiro having as pedagogical proposal the use of Museu da Maré as an example of Anti / Contra / Decolonial pedagogy that can be used in the classroom as a way to counter a traditional Eurocentered historiography. The museological and epistemological experience of the Museu da Maré offers us didactic subsidies for a historiography aligned to subalternized groups, when it uses elements of Popular Education, aligned with that of Anti / Contra / Decoloniality in its practices.
\end{abstract}

Keywords: Anti / Contra / Decoloniality; History Teaching; Museu da Maré. 


\section{Introdução}

Este artigo tem como finalidade, lançar um olhar sobre o ensino de História, dentro de uma perspectiva pedagógica que compreenda a prática docente como um conjunto de ações em sala de aula que tenha o potencial de se contrapor a um currículo escolar marcado por narrativas coloniais. Para tanto, poucos exemplos seriam mais emblemáticos do que uma experiência de museologia social como a que encontramos no Museu da Maré, no sentido de analisar sua influência como uma ferramenta poderosa de materialização efetiva de uma educação popular no cotidiano da escola pública.

O referido Museu periférico foi erguido no maior conjunto de favelas da cidade do Rio de Janeiro, onde se vê de maneira constante, ações do poder público cujo objetivo se constitui em, supostamente, combater o tráfico de drogas. Um lugar que se mostra estereotipado pela sociedade e pelas corporações midiáticas, sendo visto historicamente como um local violento e composto por pessoas potencialmente suspeitas.

Foi justamente dentro desse contexto social que o Museu da Maré foi pensado e criado com uma proposta de narrativa que de alguma maneira pudesse fazer contraponto às historiografias tradicionais caracterizadas, principalmente, por olhares eurocentrados sobre a própria história do Brasil. Era uma tentativa, portanto, de apresentar para o público morador de uma periferia urbana que inúmeras histórias podem ser contadas sim, também do ponto de vista dele. Histórias aonde sua ancestralidade também pode figurar nos salões da memória nacional, assim como seus feitos ao longo do tempo, seu esforço pela sobrevivência e suas conquistas que atravessaram gerações.

Dentro dessa perspectiva, uma das ações pedagógicas que o Museu da Maré tem levado à frente no território, tem sido exatamente a de estabelecer um diálogo permanente com as escolas públicas da região, no sentido de apresentar nas salas de aula, narrativas historiográficas de caráter Anti/Contra/Decolonial. Narrativas, portanto, que questionam um ensino de História permeado de colonialidades e se apresentam na prática docente como formas questionadoras dos currículos pautados pelo eurocentrismo. Concomitante a isso, o Museu da Maré se constitui também, como uma ferramenta essencial de Educação Popular, na medida em que oferece para a prática docente, possibilidades 
concretas de se (re)construir um conhecimento do ponto de vista de populações historicamente subalternizadas, solidificando dessa forma, consciências críticas na percepção de um mundo hierarquizado e marcado pela lógica da exploração. Tal panorama de constatação do Museu da Maré como uma ferramenta importante da Educação Popular nas escolas públicas do território nos leva também, neste artigo, a compreender com um pouco mais de profundidade, justamente, a própria constituição teórica desse tipo de pedagogia questionadora.

\section{Educação Popular de base Anticolonial}

Em contraponto com uma educação mecanizada, a Educação Popular se inventa, reinventa, e dentro disso, rompe com as práticas tradicionais-conservadoras por meio de uma insurgência epistemológica contra os modelos pré-fabricados de construção do conhecimento. Assim, por ter essa sua característica mambembe, não cabe em formato de escrita e ações previamente estabelecidas, é, portanto, inovadora em sua essência. São assim experiências “extraordinariamente pedagógicas” (BORON, 2006). É este tipo de pedagogia "extraordinária", que chamamos de crítica, que contextualiza e problematiza processos de construção do conhecimento, que aqui chamamos "mais do mesmo", padronizados e que, por sua vez, contribuem apenas para a involução de processos e projetos emancipatórios de sociedade. E são inúmeras as experiências educativas que se comprometem de fato com seu tempo, com a história, com mudanças reais e que, por sua vez, podem estar separadas de acordo com as suas demandas específicas, mas encontramse em perfeita consonância quando o assunto é o rompimento com as pedagogias conservadoras tradicionais: "Trata-se, em síntese, de uma construção alternativa à modernidade eurocêntrica, tanto no seu projeto de civilização quanto em suas propostas epistêmicas" (OLIVEIRA \& CANDAU, 2010: 17). Deste modo, não se trata de 'produzir', mas construir e reconstruir conhecimentos, bem como questionar saberes canonizados. Não seria negar estes últimos, tampouco apenas inseri-los nos debates e currículos, mas seria a pressuposição à transformação, questionando as bases ideológicas de um saber milenarmente construído e legitimado.

A elaboração intelectual do processo de modernidade produziu uma perspectiva de conhecimento e um modo de produzir conhecimento que 
demonstram o caráter do padrão mundial de poder: colonial/moderno, capitalista e eurocentrado. Essa perspectiva e modo concreto de produzir conhecimento se reconhecem como eurocentrismo. Eurocentrismo é, aqui, o nome de uma perspectiva de conhecimento cuja elaboração sistemática começou na Europa Ocidental antes do século XVII, ainda que algumas de suas raízes são sem dúvida mais velhas, ou mesmo antigas, e que nos séculos seguintes se tornou mundialmente hegemônica percorrendo o mesmo fluxo do domínio da Europa burguesa. Sua constituição ocorreu associada à específica secularização burguesa do pensamento europeu e à experiência e às necessidades do padrão mundial de poder capitalista, colonial/moderno, eurocentrado, estabelecido a partir da América. (QUIJANO, 2005: 9)

É a partir do século XVI que o conceito de ocidentalismo entra em voga e com ele toda a legitimação para se dominar e explorar os sem-alma, sem religião, sem cultura, sem língua, sem história. É com base neste mundo moderno/colonial que irão se configurar as teorias evolucionistas de homem e a obrigação de seguir este modelo único de 'humano'.

Esse primeiro grande discurso que inventa, classifica e subalterniza o outro é também a primeira fronteira do nascente sistema mundo moderno/colonial. Do ponto de vista político-filosófico essa fronteira é estabelecida pelo princípio da 'pureza de sangue' na península ibérica - que estabeleceu classificações e hierarquizações entre cristãos, mouros e judeus - e pelos debates teológicos da Escola de Salamanca em torno dos 'direitos dos povos', que definiu a posição de indígenas e africanos na escala humana (DUSSEL, 1994). Esse primeiro grande discurso que impôs as primeiras diferenças coloniais no sistema mundo moderno/colonial passa, posteriormente, por sucessivas transformações, tais como o racismo científico do século XIX, a invenção do oriental, a atual islamofobia etc. (GROSFOGUEL e COSTA, 2016: 18)

Dentro desta perspectiva, não há que se ir muito longe para reconhecermos em

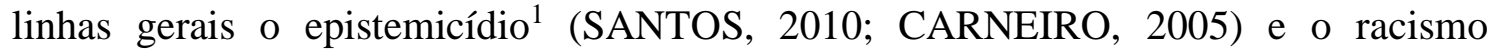

\footnotetext{
${ }^{1}$ Boaventura de Souza Santos desenvolveu o conceito de Epistemicídio, que é um movimento que trata de aniquilar qualquer sabedoria de povos considerados aquém de demais civilizações, no caso os europeus, frente aos povos indígenas e africanos, por exemplo. Seria assim um genocídio de suas epistemes, de suas práticas, de suas místicas, de seus costumes, visando à imposição da história única, de um saber não-plural, mas ancorado em bases europeias de sustentação e difusão. Essencialmente racista e classista, por assim
} 
epistêmico ${ }^{2}$, como um projeto de sociedade. O século XX nos mostra dentro de centros de produção e elaboração do conhecimento, formas de subalternização positivistas e eugenistas bem firmadas: “com efeito, foi neste contexto demográfico que se desenvolveu um padrão de estética social, em cuja escala de valores a cor escura ocupa, por assim dizer, o pólo negativo.

Quando, se prevalecessem, aí critérios sociais não heteronômicos, o contrário é que deveria ter acontecido" (GUERREIRO RAMOS, 1995: 226). A noção de progresso em diferentes áreas das ciências, que alguns autores nos mostram, vai nos levar a entender quão grande era a dominação europeia em seus vários quadros de atuação, em que a perspectiva evolucionista de sociedade previa que os "povos selvagens" poderiam (alguns somente) chegar um dia a patamares de evolução tal qual a Europa já havia atingido. Como exemplos, temos Hegel que afirmava que a África não possuía história, e o inglês Herbert Spencer, apontado como o fundador do racismo científico, quando classificou os povos entre superiores e inferiores, estando indianos e indígenas na segunda posição e europeus na primeira. Já no Brasil, tiveram ressonância as ideias do médico Raimundo Nina Rodrigues, com sua interpretação do evolucionismo social, que por meio de seu racismo científico, inferiorizava e negava a cultura indígena e africana. Essa hegemonia da episteme moderna irá adentrar em todos os acessos possíveis da sociedade, sobretudo na política, na economia, nas relações e, principalmente, na educação.

Como nos reforça Muryatan Barbosa,

Nestas perspectivas francamente eurocêntricas, as sociedades e os povos 'prémodernos' ou 'arcaicos' deveriam ser estudados como estágios de um caminho civilizacional único, cujo ápice seria a Europa Ocidental. Assim, pois, o passado destas sociedades deveria ser um exemplo inicial deste processo evolutivo. Em todos os casos citados, se reproduz, portanto, a crença na excepcionalidade europeia, definida de diversas formas. Desde uma compreensão econômico-social (o capitalismo); culturalista (modernidade,

\footnotetext{
dizer. No Brasil, a maior referência no assunto é a filósofa Sueli Carneiro, que em sua tese de doutoramento pela Universidade de São Paulo, em 2005, afirma que o epistemicídio é um "fenômeno que ocorre pelo rebaixamento da auto-estima que o racismo e a discriminação provocam no cotidiano escolar; pela negação aos negros da condição de sujeitos de conhecimento, por meio da desvalorização, negação ou ocultamento das contribuições do Continente Africano e da diáspora africana ao patrimônio cultural da humanidade; pela imposição do embranquecimento cultural e pela produção do fracasso e evasão escolar. A esses processos denominamos epistemicídio".

2 Para o aprofundamento deste conceito, ver mais em: GROSFOGUEL, Ramón (2011). Racismo Epistêmico, Islamofobia Epistêmica e Ciências Sociais Coloniais. Tabula Rasa [online]. n.14: .341-355. ISSN 1794-2489.
} 
cultura greco-romana); religiosa (judaico-cristã); racial ('branca'), etc. (2008: 48)

Mas quem eram esses ditos "selvagens, primitivos"? A resposta a esta pergunta não pode ser feita somente no passado, isto porque este tipo de ideologia ainda está muito presente nas relações sociais e nas instituições. Assim: "quem são esses ditos 'selvagens, primitivos'?" Seria este o ponto de partida para as nossas análises, quando estaria mais correto e honesto o esmiuçar do termo em conjunto com sua atualidade. A começar porque a "epistemologia eurocêntrica ocidental dominante, não admite nenhuma outra epistemologia como espaço de produção de pensamento crítico nem científico" (GROSFOGUEL, 2007: 35), o que resulta como uma das formas de manutenção de históricos privilégios de determinadas classes e raças sobre outras.

Sob a égide do progresso, a caminhada da "civilização" desde as cruzadas até a Guerra Fria e, sim, até os dias atuais, têm nos mostrado que é por outro viés que se opera esta ideia de 'progresso'. Pautadas na exploração e apropriação de terras e seus povos, de sua biodiversidade e de sua propriedade intelectual, por meio da escravização, matanças e genocídios, o que vemos nestas construções ideológicas de progresso são verdadeiras barbáries pouco midiatizadas pelos grandes equipamentos de comunicação e organismos internacionais e muito contadas pelos vieses de uma minoria, sobretudo hegemônica e branca, de forma a descartar assim a "perspectiva da maioria das pessoas do planeta cujas vidas foram declaradas dispensáveis, cuja dignidade foi humilhada, cujos corpos foram usados como força de trabalho" (MIGNOLO, 2013: 296) como meio de alimentar a economia do capital e manter privilégios.

Como Guerreiro Ramos (1995: 220) bem observa,

Para garantir a espoliação, a minoria dominante de origem europeia recorria não somente à força, à violência, mas a um sistema de pseudojustificações, de estereótipos, ou a processos de domesticação psicológica. A afirmação dogmática da excelência da brancura ou a degradação estética da cor negra era um dos suportes psicológicos da espoliação.

Existia uma espécie de combinação entre a ordem política conservadora e o progresso econômico, ambos apoiados por um sistema de educação em formação. Tratase de uma dependência histórico-estrutural" (MORETTI; STRECK, 2013: 36). Pensar enquanto povo subalternizado, sobretudo as populações latino-americanas e africanas, 
que foram e são historicamente silenciadas em toda a sua estrutura social é romper e desafiar discursos e estratégias que desqualificam e apontam carências no lugar de possibilidades, fragmentação no lugar de ajuntamento. É perceber ainda que os saberes da rua e dos povos tradicionais podem e devem sim ser levados em consideração neste processo, de forma a entrar no currículo das escolas. Por sua vez, os espaços de educação, sejam eles formais ou não-formais, devem tornar-se definitivamente amplos espaços e palcos para esse debate, concatenando, o que poderíamos chamar de epistemes-outras, de forma a desvelar pouco a pouco o histórico de preconceitos e estereótipos e demais violências físicas e simbólicas que nossa ancestralidade oprimida experimentou. Pois foi “graças à colonialidade, [que] a Europa pode produzir as ciências humanas como modelo único, universal e objetivo na produção de conhecimentos, além de deserdar todas as epistemologias da periferia do ocidente (OLIVEIRA \& CANDAU, 2010: 17).

\section{Discussão}

Dentro desse recorte epistemológico e ao mesmo tempo combativo, é inspiradora para esta caminhada a articulação dos referenciais da Educação Popular (EP) com os da Anti/Contra/Decolonialidade, cruzando por meio dessas experiências pedagógicas as heranças da colonialidade nos 'territórios do sul' ${ }^{3}$. A EP assim se insere na genealogia do pensamento crítico Anti/Contra/Decolonial, enquanto prática e pesquisa social, ação e movimento, ligada a projetos de emancipação no fortalecimento de uma pedagogia outra em nosso continente, que é aquela que coloca em xeque a episteme europeia com seu ideal branco, historicamente hegemônico. Isto posto, pensamos que a Anti/Contra/Decolonialidade e a EP por si se referem a "transgredir, deslocar e incidir na negação ontológica, epistêmica e cosmogônico-espiritual que foi - e é - estratégia, fím e resultado do poder da colonialidade" (WALSH, 2009: 27).

Colonialidade e Modernidade são pares pensados e não derivados um do outro, que apontam para um discurso de base hegemônica servil. A colonialidade, neste fim, é apenas um dos muitos efeitos da colonização e da modernidade, dominação e progresso,

\footnotetext{
${ }^{3}$ Entendemos por "territórios do sul", povos oprimidos de latinoamerica, do sul global, não deixando de fora, contudo, povos de África e Ásia, que também sofrem opressões dos povos "do norte". Em outras palavras, o que se entende por sul, são povos fora da Europa e Estados Unidos que sofreram (e até hoje sofrem) as consequências das expansões capitalistas, que expropriou as riquezas materiais e aniquilou muitas das culturas dos povos do sul.
} 
legitimando formas de opressão (colonialidade), da negação de direitos e modos de ser, que tem nas instituições e na burocracia seu braço acordal. $\mathrm{O}$ racismo, o machismo, a fome são premissas deste modo de viver nesta sociedade (MIGNOLO, 2007), são suas consequências mais perversas e que tem na Anti/Contra/Decolonialidade uma grande rival, esta que denuncia frequentemente e ferozmente seu caráter arbitrário, insurgindose contra elas. Por outro lado, lutar pela e com a Anti/Contra/Decolonialidade não significa repelir os saberes europeus ou romantizar o passado ameríndio e africano, mas ter como ponto de partida a problematização da realidade opressora que historicamente vem se consolidando em paradigmas a serem seguidos. Em outras palavras, não é se desconectar dos saberes sistematizados, mas ampliar estes conhecimentos na perspectiva também da problematização da real necessidade deste tipo de saber à prática cotidiana do grupo em questão. É assim, "ler Gramsci, mas também ouvir o Gramsci popular nas favelas" (TORRES, 1996: 141). Para além de uma educação popular que capacite tecnicamente as camadas populares, o que se coloca em primeira linha é a insurgência dos saberes e povos, Reconstruindo conhecimentos com outras significações e para outros significantes e significados. Seria assim o sujeito partindo de um 'não-ser', se desvelando no 'vir-a-ser', como entendedor e propagador de sua própria história, porque agora carregada de sentidos. Vendo na colonização seu algoz, este sujeito passa a não mais viver, mas a existir, não a negar sua própria ancestralidade, mas a reconhecer-se nela e com ela.

O projeto Anti/Contra/Decolonialidade requer a equalização de conhecimentos, pois não interessa neste caso somente a restituição ou reparação de conhecimentos, mas, sobretudo o desafio de se pensar a partir das margens, das periferias do saber, do poder e do ser (QUIJANO, 2005). Seria valorizar nossas epistemologias e recriá-las para que se legitimem também conhecimentos que estão localizados em seus interiores, nas margens, nas periferias, onde silenciados e desqualificados foram historicamente seus saberes e práticas.

A perspectiva da diferença colonial requer um olhar sobre enfoques epistemológicos e sobre as subjetividades subalternizadas e excluídas. Supõe interesse por produções de conhecimento distintas da modernidade ocidental. Diferentemente da pós-modernidade, que continua pensando tendo como referência o ocidente moderno, a construção de um pensamento crítico "outro", parte das experiências e histórias marcadas pela colonialidade. O eixo 
que se busca é a conexão de formas críticas de pensamento produzidas a partir da América Latina, assim como com autores de outros lugares do mundo, na perspectiva da decolonialidade da existência, do conhecimento e do poder. (OLIVEIRA \& CANDAU, 2010: 23-24)

É dentro de uma aposta de superação e transposição à colonialidade nas pedagogias, que a Educação Popular se configura como um processo aberto e contínuo, não involuntário, tampouco finito e com apenas uma frente de atuação. Diferente disto a EP se contrapõe de maneira frontal aos processos de educação que tradicionalmente serviram para a formação de uma não-cidadania, num contexto de subalternização das classes, elegendo uns em detrimento de outros. Escolhendo quem serviria e quem seria servido à mesa. Para além de um formato dual e adestrador, não seria de forma alguma "dirigir as massas", mas conduzir e mediar o processo de criar, recriar e problematizar conhecimentos. A dialogicidade, portanto, se faz presente de forma radical neste tipo de relação. Em consonância com a perspectiva Anti/Contra/Decolonial, a EP prevê a saída dos espaços periféricos de uma epistemologia subalternizada rumo à uma epistemologia onde a participação do outro se transporte destes espaços periféricos para o centro dos processos educativos, porque coletivos e coletivizados. Ter lentes que aproximem sua luta à de outros e outras nos traz a percepção de que não se está sozinho e o sujeito individual só o é porque tem no coletivo sua chave para a existência. Sendo assim, o devir: o vir-a-ser se constrói antes da luta, quando se descobre enquanto colonizado. E esta descoberta só se dá na práxis cotidiana de pensamento-reflexão-ação. E é justamente no "reconhecimento do seu pouco saber de si que se formará uma das razões desta procura" (FREIRE, 2005: 29).

A Modernidade nasce realmente em 1492: essa é a nossa tese. Sua real superação (como subsuntion e não meramente como Aufhebung hegeliana) é a subsunção de seu caráter emancipador racional europeu transcendido como projeto mundial de libertação de sua Alteridade negada: a Trans-Modernidade (como novo projeto de libertação político, econômico, ecológico, erótico, pedagógico, religioso, etecetera). (DUSSEL, 2000: 50-51)

$\mathrm{Na}$ esteira do processo de colonialidade, o que se trata, portanto é de um projeto epistêmico bem alinhavado e articulado em várias teias, que sobrevive bem até os nossos dias, e se torna a cada dia mais imperceptível do ponto de vista tangível, mas que cumpre 
seu papel perversamente velado. Eram assim o espanhol e o português na América dos séculos XVI ao XX, passando à França do início até meados deste mesmo século e deslocando o bastão para os "cuidados" dos EUA para continuar o legado epistêmico colonial em nossas terras, chegando ao que temos hoje.

Pensamos assim que, apesar de não vivermos mais num regime colonial formalmente - o que não se quer dizer que não se viva e conviva com ele em sua forma ideológica, por meio de imposições e embargos políticos, econômicos e judiciários- a colonialidade está plenamente vivificada quando ela sobrevive nessas formas sutis de arranjo e rearranjo na sociedade, fabricando e moldando seres, por meio de uma falsa cidadania, por meio de uma falsa inclusão. É ainda, quando o que se chama aqui de colonizador começa por meio de seus privilégios a invisibilizar e destruir a imagem e o imaginário do outro, bem como seus sonhos e esperança, afirmando assim hegemonicamente sua visão de mundo e o que considera como passível de se tornar legítimo, prestigioso e abrangente. Assim, temos a escrita, a forma como se fala, os gestos, a "etiqueta", o "certo" e o "errado", o CEP, a cor, a sexualidade e a estética corporal para dar a tonalidade final a estes exemplos vivos de uma colonialidade cotidiana de "sucesso".

\section{A colonialidade/Modernidade: um sistema-mundo de narrativas e memórias de apagamento de narrativas e memórias outras}

A modernidade que para os europeus foi um processo de ruptura com o passado, contraditoriamente se instituiu repleta de permanências em sua construção histórica. Essa contradição do modo de viver moderno se expande para além do continente europeu sob as formas do colonialismo perpetuados na colonialidade. A decolonialidade sempre existiu na forma de resistência, nas lutas empreendidas pelos povos originários e escravizados como reação ao expansionismo genocida europeu sobre “Abya Yala” 4 já

\footnotetext{
${ }^{4}$ Abya Yala na língua do povo Kuna significa "Terra madura", "Terra Viva" ou "Terra em florescimento" e é sinônimo de América. O povo Kuna é originário da Serra Nevada no norte da Colômbia tendo habitado a região do Golfo de Urabá e das montanhas de Darien e vive atualmente na costa caribenha do Panamá na Comarca de Kuna Yala (San Blas). Abya Yala vem sendo usado como uma autodesignação dos povos originários do continente como contraponto a América expressão que, embora usada pela primeira vez em 1507 pelo cosmólogo Martin Wakdseemüller, só se consagra a partir de finais do século XVIII e inícios do século XIX por meio das elites crioulas para se afirmarem em contraponto aos conquistadores europeus no bojo do processo de independência. Muito embora os diferentes povos originários que habitam o continente atribuíssem nomes próprios às regiões que ocupavam - Tawantinsuyu, Anauhuac, Pindorama - a expressão
} 
que o termo américa é uma invenção dos europeus.. A defesa das existências, material e imaterial, memórias e narrativas destes povos permanecem em andamento, pois o colonialismo ainda está presente. Como vimos acima, o projeto Anti/Contra/Decolonial, anterior a qualquer concepção teórico-científico-política, traz consigo a radicalidade ancestral de defesa de existências historicamente apagadas, exterminadas pelo sistema mundo da civilização européia. A centralidade, sob a perspectiva dos povos originários e que está para além de ser mais do que uma teoria acadêmica, é a manutenção de um projeto ético-político capaz de destruir as estruturas que dão sustentação às permanências do mundo colonial, no caminho de ser Anti/Contra/Decolonial. Assim, os processos de dominação instaurados pelo colonialismo e que forjaram as narrativas e memórias que dão sustentação à colonialidade do poder estão estruturados nos valores da branquitudepatriarcal-capitalista, como "as identidades construídas pelos discursos europeus modernos eram raciais (isto é, a matriz racial colonial) e patriarcais" (MIGNOLO, 2018). Nas palavras de Quijano:

Por outro lado, o atual, o que começou a formar-se com a América, tem em comum três elementos centrais que afetam a vida cotidiana da totalidade da população mundial: a colonialidade do poder, o capitalismo e o eurocentrismo. Claro que este padrão de poder, nem nenhum outro, pode implicar que a heterogeneidade histórico-estrutural tenha sido erradicada dentro de seus domínios. O que sua globalidade implica é um piso básico de práticas sociais comuns para todo o mundo, e uma esfera intersubjetiva que existe e atua como esfera central de orientação valorativa do conjunto. Por isso as instituições hegemônicas de cada âmbito de existência social, são universais para a população do mundo como modelos intersubjetivos. Assim, o Estado-nação, a família burguesa, a empresa, a racionalidade eurocêntrica. (QUIJANO, 1989: 169).

Os processos históricos de independência política das colônias espanholas e portuguesas durante o século XIX não foram capazes de produzir rupturas significativas que permitissem que com o fim do colonialismo das monarquias européias a colonialidade, também, chegasse ao seu fim. Os valores do sistema-mundo europeu

Abya Yala vem sendo cada vez mais usada pelos povos originários do continente objetivando construir um sentimento de unidade e pertencimento (PORTO-GONÇALVES, Carlos Walter. Verbete da Enciclopédia latinoamericana. 2015.) 
permaneceram presentes na vida social através de diversos padrões de poder sob a forma de saberes, do pensar, do vestir, do falar, da religiosidade, das narrativas e memórias. As relações de subalternidade impostas durante o colonialismo e tiveram poucas rupturas com os movimentos sociais de emancipação políticas na relação colônia-metrópole, porém muitas permanências em distintos aspectos da vida social entre os subalternos.

O expansionismo comercial Europeu movimentou essa estrutura de dominação cultural em direção ao hemisfério sul, impondo seus valores e costumes aos povos originários da América. Neste sentido, a Anti/Contra/Decolonialidade caminha nas criação das permanências e rupturas, do colonialismo, para que outras formas de viver, sentir, pensar, existir, se emancipem das colonialidades do poder, herança dos processos históricos da colonização europeia. O processo de emancipação das colônias, realizado no século XIX, se deu no campo político, porém a mentalidade colonial, ainda, está presente na sociedade nas construções histórico-sociais de classe, gênero e raça. Esse pensamento colonial é significativamente presente nos conteúdos programáticos, nos currículos escolares, nas pedagogias tradicionais conservadoras, da reprodução de um projeto de sociedade de determinados grupos hegemônicos no chão da escola pública.

Diante da complementaridade entre Educação Popular e Pedagogia Anti/Contra/Decolonial frente a necessidade de uma educação voltada para um projeto de “sociedade-sujeito", como disse Paulo Freire, potencializadora de uma visão crítica sobre a realidade que aponte para a superação das desigualdades que ainda marcam a nossa sociedade, a pergunta-provocação que fica é: como realizar Educação Popular na Escola Pública, um espaço de educação que tem dificuldades em dialogar com as demandas dos educandos provenientes das camadas populares, maioria nas escolas públicas?

\section{"Professor, por que no livro tem mais páginas de Grécia e Roma do que de África e "índios"? (pergunta de um estudante do ensino médio)}

É bem provável que muitos educadores tenham ouvido essa pergunta de algum estudante em suas aulas de história. O currículo universitário nos "ensinou" com propriedade através de uma vasta bibliografia e defesas dos conteúdos, narrativas que posicionam a Europa como centro de produção do conhecimento, da cultura, da ciência e dos saberes : o Eurocentrismo. 
A colonialidade está presente não somente nas narrativas e memórias armazenadas nos livros, mas sobretudo na reprodução de práticas pedagógicas conservadoras, conteudistas e tecnicistas que se materializam em colonialidades pedagógicas.

No próximo ítem relataremos nossas vivências, experiências em sala de aula a partir de uma pedagogia Anti/Contra/Decolonialidade.

\section{O Museu da Maré e suas contribuições à prática docente Anti/Contra/Decolonial no ensino da história}

O Museu da Maré é um exemplo de pedagogia Anti/Contra/Decolonial a ser usada em sala de aula como uma forma de contrapor uma historiografia tradicional eurocentrada. Isto porque o espaço de cultura e educação não-formal que constitui o referido museu é uma experiência de construção coletiva da ação direta de moradores da localidade no resgate da memória e (re)construção de narrativas, de saberes não registrados formalmente e que ainda não estão presentes no cotidiano das aprendizagens de nossos estudantes. A atuação do Museu da Maré, pautada nos referenciais da Educação Popular, permite evidenciar as verdades silenciadas resgatadas por seus moradores, sujeitos sociais, em sua dimensão simbólica, material e imaterial enquanto memória, oralidade e narrativas históricas de um território marcado de estigmas resultantes da colonialidade, sobretudo do racismo epistêmico.

A experiência museológica-outra do Museu da Maré provoca diversas percepções e chaves de leituras que contribuem na prática docente do ensino de história, já que essa experiência se fundamenta na dimensão problematizadora dos processos de reconstrução do conhecimento. Uma das principais contribuições é o fato de através da prática educativa, de posse das novas narrativas, conectar nossos estudantes à prática social sob a perspectiva de um fazer decolonial. Esta ação direta se torna fruto das convergências de nossas experiências, militâncias e estudos sobre Educação Popular e o pensamento Anti/Contra/Decolonial. A proposta museológica do Museu da Maré vem ao encontro de nossas inquietações e práticas docentes, na busca e ação da superação de uma educação desconectada da realidade, que não contempla as especificidades materiais e subjetivas dos nossos educandos: periféricos, favelados, filhos e filhas das camadas populares empobrecidas. 
Seguimos com essas práticas cotidianas de uma outra educação mobilizados por essas percepções e enraizados em uma prática pedagógica crítica enquanto educadores de espaços formais e não formais de educação, com os pés no "chão" da escola pública e dos pré-vestibulares comunitários ${ }^{5}$, propondo a tecer Educação Popular e a Educação Anti/Contra/Decolonial em vários espaços e cenários que nos cabem. O educando que frequenta as escolas públicas, geralmente, é pertencente às camadas populares empobrecidas, oriundos das periferias e favelas. Um estudante periférico da periferia do mundo, que resiste pela sua existência frente a uma sociedade que o silencia em um espaço de educação, que o objetifica, o adestra. Esse educando carrega marcadores sociais da diferença estabelecidos a partir da régua dos valores, das estruturas de poder do colonialismo, do eurocentrismo. Esses estigmas são legitimados durante a sua vida de estudante, na educação-escolar, em um processo de ensino-aprendizagem que não contempla a sua realidade, sua existência, seus saberes. Uma dinâmica educacional que não temporaliza este educando, que não utiliza a Educação Popular e a Pedagogia Anti/Contra/Decolonial, enquanto proposta contra-hegemônica, disponibilizando outras formas de viver, pensar, sentir, existir e re-existir.

Diante desse caminho analítico é possível compreender a importância do Museu da Maré enquanto concepção e ação pedagógica tecida na experiência histórica das lutas dos movimentos sociais em defesa de narrativas referenciadas por grupos subalternizados insurgentes. Este fazer e agir do museu realiza o registro de memórias fundamentadas nos saberes populares, na emancipação popular capaz de colaborar na concretização de outro projeto de sociedade, anticolonialista, como ato político e ainda como agente de transformação social e política.

\section{Na prática, o Museu da Maré como ferramenta pedagógica Anti/Contra/Decolonial na aula de história}

O Museu da Maré oferece elementos que permitem desenvolver práticas pedagógicas anti/contra/decoloniais atuando diretamente sobre o Currículo Mínimo do

\footnotetext{
${ }^{5}$ Pré-Vestibulares Comunitários se inserem num contexto de luta pela democratização e universalização do acesso ao ensino superior que surgem em meados da década de 80 do século XX. Tais iniciativas são caracterizadas pela participação expressiva de jovens das periferias urbanas e favelas no sentido de romper com as desigualdades educacionais frente ao privilégio que historicamente marcou o acesso à universidade pública no Brasil. Os pré-comunitários se consolidaram junto aos movimentos sociais e populares atuando junto aos sindicatos, igrejas e espaços de favelas. (ZAGO, 2008)
} 
Ensino Médio utilizado na rede estadual de ensino do Rio de Janeiro. A historiografia presente nos livros didáticos ainda é permeada de narrativas eurocêntricas que evidenciam os valores e princípios da modernidade/colonial. Esse cenário exige dos educadores de história um olhar descolonizado, no sentido de nos apropriarmos de propostas pedagógicas comprometidas com críticas à colonialidade dos saberes. O Museu da Maré torna-se uma alternativa anticolonialista quando produz rupturas com a produção de conhecimento da historiografia eurocêntrica.

No primeiro bimestre, nas turmas de $1^{\mathrm{o}}$ ano do ensino médio, temos a oportunidade de debater conceitos como História, Cultura, patrimônio e tempo. Conceitos moldados e elaborados sob os marcos do mundo moderno civilizatório fundadas em processos de dominação e padrões de poder, conforme as palavras de Quijano (2005):

A América constitui-se como o primeiro espaço/tempo de um padrão de poder de vocação mundial e, desse modo e por isso, como a primeira id-entidade da modernidade. Dois processos históricos convergiram e se associaram na produção do referido espaço/tempo e estabeleceram-se como os dois eixos fundamentais do novo padrão de poder. Por um lado, a codificação das diferenças entre conquistadores e conquistados na idéia de raça, ou seja, uma supostamente distinta estrutura biológica que situava a uns em situação natural de inferioridade em relação a outros. Essa ideia foi assumida pelos conquistadores como o principal elemento constitutivo, fundacional, das relações de dominação que a conquista exigia. Nessas bases, consequentemente, foi classificada a população da América, e mais tarde do mundo, nesse novo padrão de poder. Por outro lado, a articulação de todas as formas históricas de controle do trabalho, de seus recursos e de seus produtos, em torno do capital e do mercado mundial. (QUIJANO, 2005: 107)

A construção das narrativas realizadas pelo Museu da Maré alinhadas aos conhecimentos, saberes e memórias dos subalternizados contribuem, em sala de aula, para que os estudantes compreendam que a construção do conhecimento não é imparcial e que todos somos sujeitos históricos.

Fazemos uma analogia da produção de conhecimento que o Museu realiza com a produção da historiográfica registrada nos livros didáticos de história, o que nos permite conversar com os estudantes sobre a relação Eurocentrismo $\mathrm{x}$ 
Anti/Contra/Decolonialidade. A partir desta relação discutimos com eles como se dá essa disputa de narrativas frente ao que se instituiu como verdade na historiografia tradicional.

O Museu da Maré faz seu percurso pedagógico, de produção de conhecimentos "outros", sob perspectivas anti/contra/Decoloniais alinhadas à educação popular no sentido de emancipação epistêmica como explica Oliveira e Candau:

A questão central num projeto de emancipação epistêmica é a coexistência de diferentes epistêmes ou formas de produção de conhecimento entre intelectuais, tanto na academia, quanto nos movimentos sociais, colocando em evidência a questão da geopolítica do conhecimento. Como visto anteriormente, entende-se geopolítica do conhecimento como a estratégia da modernidade europeia que afirmou suas teorias, seus conhecimentos e seus paradigmas como verdades universais e invisibilizou e silenciou os sujeitos que produzem conhecimentos 'outros' $\underline{5}$. Foi esse o processo que constituiu a modernidade que não pode ser entendida sem se tomar em conta os nexos com a herança colonial e as diferenças étnicas que o poder moderno/colonial produziu. (OLIVEIRA \& CANDAU, 2010)

A escrita da História é uma permanente busca de verdades que em um determinado processo histórico-social não foi selecionada como narrativa oficial para ser perpetuada como memória. A seleção das verdades que o Museu da Maré realiza para reescrever a história da Maré coloca a classe trabalhadora: favelada e periférica como centralidade desse processo. O Museu da Maré faz História Social, rompe com o padrão epistemológico de produção de conhecimento estabelecido na relação objeto-sujeito, posicionando todas e todos os envolvidos como sujeitos históricos e sociais, protagonistas desse processo.

É dentro de um processo dialógico que apresentamos aos nossos educandos a possibilidade de re-construir a leitura do mundo sob o olhar descolonizado, na perspectiva de que eles reflitam sobre como a historiografia tradicional foi pensada nos marcos da história européia. Ressaltamos assim a importância do estudo da disciplina de história, que a história faz parte da vida deles, pois faz as conexões entre passado e presente, contribuindo para que eles desenvolvam uma leitura crítica, como afirma Paulo Freire: "a leitura do mundo precede a leitura das palavras" (FREIRE, 1989). Os estudantes são levados a refletir como a História explica o que mudou e o que não mudou na história da humanidade, como o racismo, o machismo e a pobreza no Brasil, as 
desigualdades sociais ainda fazem parte do cotidiano de nossas vidas. Baptista (2020) escreve em sua dissertação sobre o Museu da Maré sobre a importância das narrativas e dos sujeitos contemplados a partir da atuação do museu:

Constatamos também, que o Museu em funcionamento produz, através de suas exposições, diferentes linhas de contra-narrativas, onde as imagens de pessoas, objetos e ambientes locais estão na centralidade. É como se através dessa ampla produção sócio-museal, nossos interlocutores estivessem reposicionando antigos habitantes da favela no debate contemporâneo. (BAPTISTA, 2020: 33)

Em outro momento da aula, contextualizamos como o Museu construiu seu acervo, o que nos permite dialogar sobre fontes históricas. Usamos o exemplo do acervo do museu como instrumento didático para falarmos sobre fontes históricas: escritas, orais, materiais, imagéticas e como essas fontes nos ajudam a reconstituir o passado e colocar em evidência as verdades silenciadas dos grupos subalternos. Não existe História sem fontes. Neste momento são mostradas imagens das fontes históricas que fazem parte do acervo do museu: pertences de antigos moradores, fotos, dentre outras e a reprodução de uma palafita em tamanho real.

Uma parte dos estudantes são moradores de favela e percebemos um processo de identificação com a proposta do museu, tendo em vista que suas realidades são contempladas, há uma identificação. É uma experiência muito rica pois o olhar é de surpresa ao saber que existe um museu em uma favela e que esse museu valoriza os saberes e experiências dos grupos sociais aos quais eles estão inseridos, é uma história em que eles se reconhecem.

O Museu da Maré se faz pedagógico através da sua presença física, pois materializa as subjetividades e simbolismos negados, tornando-se lugar de memória, história e, consequentemente, cultura. As exposições realizadas pelo Museu da Maré nos permitem refletir, com os alunos, sobre o "tempo e suas durações", um conceito muito usado no ensino da história.

O historiador francês Fernand Braudel, classificou os acontecimentos históricos como sendo de curta duração (fato breve: descoberta de uma vacina), média duração (acontecimentos conjunturais: Revolução Francesa) e longa duração (acontecimentos estruturais: capitalismo). Não temos a intenção de aqui fazer o debate teórico da obra de 
Braudel, mas apenas indicar como suas elaborações pautam o ensino da história e como utilizamos as exposições do museu para debater outras percepções de tempo, evidenciando outros modos e ritmos de vida, sobretudo o direito da percepção do tempo como uma construção cultural.

Apresentamos aos nossos educandos as percepções de tempo dos povos originários e africanos, como esses povos entendem o tempo. Usamos em sala de aula, como exemplo, a exposição de longa duração do museu, dividida em 12 tempos/temas para demonstrar como a concepção de tempo pode ser realizada de forma anticolonial levando em consideração as especificidades culturais dos moradores, de como percebem e sentem o tempo. Os alunos, neste momento, são orientados a confeccionar um texto sobre suas vidas, organizando o tempo no formato de temas. As divisões realizadas são as mais interessantes e diversas possíveis, como por exemplo: tempo da infância, tempo de quando eu morava com minha mãe, tempo da escola, tempo da saudade, tempo do baile, tempo que "não volta mais", dentre outros exemplos.

Outra contribuição do Museu da Maré para a nossa prática docente se dá, quando, ao resgatar as histórias silenciadas, esquecidas do território, esse movimento abre brechas para que possamos avançar na ação pedagógica de debater, valorizar e da promoção das culturas e saberes indígenas e africanos nas escolas públicas. Ao recuperar a história do território e consequentemente a história do Rio de Janeiro, o museu contribui para evidenciar não somente o nascimento e formação da Maré, mas, também, a história das populações que estiveram no período anterior à formação recente da maré.

Em sala de aula, as narrativas recuperadas dos subalternizados do passado e da história recente, deste território, são utilizadas como material pedagógico com o objetivo de promover uma educação antirracista, evidenciando: os saberes ancestrais, a construção da identidade afro-brasileira e dos povos indígenas. O Museu torna-se referência, em sala de aula, de luta e resistência contra o racismo epistêmico ao de romper com o estereótipo do colonizador partir da narrativas "outras", bem como escreveu Araújo ( 2012):

Esse capítulo foi pensado tendo em vista que a essência do Museu da Maré, seu 'conteúdo' é exatamente ressignificar, narrar, ensinar a história da Maré e construir, reelaborar as memórias locais. É claro que percebemos que cada comunidade tem sua história peculiar e todas juntas formam um todo complexo no contexto da região da Maré, compondo o mosaico do bairro de 
mesmo nome.Porém, poderíamos imaginar e pensar que há algo em comum entre tais comunidades, o que diria Lourenço César - um dos diretores do CEASM e do Museu da Maré por mim entrevistado -, '... há algo de universal nessa história que perpassa todas as comunidades da Maré', como a pesca, o carregamento da água em "rola-rola" em tempos passados, a luta pela terra, pela sobrevivência, que são retratados em diversos objetos e construções existentes dentro do Museu. (ARAÚJO, 2012).

O Museu da Maré, através de sua existência e resistência, re-afirma a sua importante contribuição se movendo em um fazer pedagógico alinhado à concepção de Educação Popular e de base Anti/Contra/Decolonial, experiências autênticas dos movimentos sociais e espaços não-formais de educação, anterior a qualquer elaboração teórico-científica e acadêmica.

O Museu da Maré é a materialização das lutas históricas, não somente das disputas por narrativas, mas sobretudo pelo direito de existir dos subalternos: dos povos originários, da população negra, dos quilombolas, das populações ribeirinhas, das favelas, das camadas populares, das trabalhadoras e trabalhadoras que, historicamente, foram submetidas às formas de existir forjados pela colonialidade.

Nossos alunos da escola pública pertencem aos grupos citados acima e se identificam com o Museu da Maré que não é potência, pois potência é "aquilo que pode vir a ser", por exemplo: uma semente pode vir a ser uma árvore; o Museu da Maré é poder, é força que irradia transformação política e social. Há muitas outras experiências em sala de aula, mas por hora ficarão aqui registradas apenas as relatadas acima.

\section{Conclusão / considerações finais}

Vamos compreender por colonização todos os processos etnocêntricos de invasão, expropriação, etnocídio, subjugação e até substituição de uma cultura pela outra, independentemente do território físico geográfico em que essa cultura se encontra. E vamos compreender por contra colonização todos os processos de resistência e de luta em defesa dos territórios dos povos contra colonizadores, os símbolos, as significações e os modos de vida praticados nesses territórios. (SANTOS, 2015:.48) 
Diante das experienciações e práticas que o Museu da Maré nos traz, constatamos que não é somente a mera inclusão de indivíduos no mercado de consumo a saída de que precisamos. Ao contrário, isto só nos faz perder de vista o foco dos movimentos e das ações, que de fato estão lutando por uma outra lógica de sociedade. Entendemos que não basta tentar extinguir a pobreza se conformando e se ajustando à lógica do capital, pois isto só altera de forma ainda mais incongruente o cenário desigual e injusto que temos na sociedade. Por este meio, desencobrir o leito ideológico que produz uma cidadania abstrata se dá através de uma cultura de divergência e questionamento, que em nosso entender seria aquela que nos levaria a uma democracia de fato cidadã ou a uma cidadania de fato democrática.

No interior desta via, a quebra da relação entre colonialidade-epistemologia se dá quando se redefine conhecimentos, saberes e experiências, bem como se reorienta e reordena a geopolítica do conhecimento, esta que operou e ainda assim o faz nos mais altos graus de pretensas universais. Um bom e oportuno exemplo disso está na geopolítica da língua em que considera-se apenas uma norma para se falar e escrever e todas as outras manifestações linguísticas são consideradas marginais, inferiores, sendo, por isso, subalternizadas. A quebra dessa relação seria assim uma "máquina" para descolonização intelectual e, portanto, para a descolonização política e econômica” (MIGNOLO, 2013: 76). Seria ainda um exercício de descolonização intelectual redefinindo e ressignificando nossos horizontes, nossa cultura, nossa língua, nosso campo político enquanto sujeitos intelectuais-históricos que somos. E a escola pública tem muito o que contribuir nessa ruptura.

Diante das reflexões fica evidente que a EP e a Anti/Contra/Decolonialidade estão muito próximas e atuam em bases comuns ao fazerem enfrentamentos e oferecerem resistência com conhecimentos dissidentes aos já consolidados, denunciando em seu bojo a exploração do capital e ainda anunciando paradigmas, palavras e valores outros como: empatia, alteridade, afetividade, autogestão, participação, coletividade, provocando desta forma a emersão de conhecimentos produzidos nas bases dos movimentos de povos e grupos subalternizados.

A Anti/Contra/Decolonialidade, em conjunto com as experiências pedagógicas de Educação Popular, estariam assim ressignificando as formas de existir de povos silenciados em inúmeros aspectos de sua condição humana. Restituindo sua condição de fala, portanto sua oralidade e história, seus corpos e culturas, enfim, sua subjetividade que 
lhes foi retirada 'à fórceps', estariam assim os dimensionando a novos horizontes e frentes, de forma a enfrentarem a colonialidade e a contribuírem para a construção e a ampliação de veias abertas de emancipação.

Por fim, é por meio desta realidade e desta senda que a Educação Popular tem seguido: uma educação não para um tempo vindouro, mas para este tempo, para o agora, de forma a criar outras relações com o mundo, que se constroem no dia a dia, nos laços de humanização que são criados nestes espaços, num olhar para a sala de aula que não abandone a vida ou que não haja uma parede entre a sala de aula e a vida real. A Educação Popular assume, com isso, um valor central na busca por humanização. É concebida, portanto, em sua dimensão ontológica, e, por conseguinte apresenta-se como possibilidade em busca da Anti/Contra/Decolonialidade.

“Que a biblioteca colonial não impeça nossa capacidade de pensar”, já nos fala a socióloga boliviana Sílvia Rivera Cusicanqui. Tampouco de agir e lutar contra essa Anti/Contra/Decolonialidade, diríamos nós!

\section{Referências bibliográficas}

ARAÚJO, Helena Maria Marques (2012). Museu da Maré: entre educação, memórias e identidades. Orientadora: Vera Maria Ferrão Candau.

BAPTISTA, Carlos Augusto (2020). Resistência e memória contra-hegemônica: um estudo sobre a luta de permanência do Museu da Maré. Orientador: Rafael Soares Gonçalves.

BARBOSA, Muryatan Santana (2008). Eurocentrismo, História e História da África. Sankofa. Revista de História da África e de Estudos da Diáspora Africana, $\mathrm{n}^{\circ} 1$ : 46-66.

BORON, A.A. (2006). Prólogo. In: RETAMAR, R. F. Pensamiento de nuestra América: autorreflexiones y propuestas. Buenos Aires: Consejo Latinoamericano de Ciencias Sociales-CLACSO: 9-14.

BRAUDEL, Fernand (2007). História e Ciências Sociais: a longa duração. In:

Escritos sobre a História. Trad. Jacob Guinsburg e Tereza Cristina Silveira da Mota. São Paulo: Perspectiva: 41-78.

CARNEIRO, Sueli (2005). A Construção do Outro como Não-Ser como fundamento do Ser. São Paulo: USP (Doutorado, Tese).

FREIRE, Paulo (2005). Pedagogia da autonomia: saberes necessários à prática educativa. São Paulo: Paz e Terra

(1995). A importância do Ato de Ler: em três artigos que se completam. São Paulo: Autores Associados. Cortez

GROSFOGUEL, Ramon (2007). Dilemas dos estudos étnicos norte-americanos: multiculturalismo identitário, colonização disciplinar e epistemologias descoloniais. Ciência e cultura. São Paulo, v. 59, n. 2: 32-35.

GROSFOGUEL, R.; BERNARDINO-COSTA, Joaze (2016). Decolonialidade e perspectiva negra. Sociedade e Estado. UnB. Impresso, v. 31: 15-24. 
GUERREIRO RAMOS, Alberto (1995). Introdução crítica à sociologia brasileira. 2 ed. Rio de Janeiro, Editora UFRJ.

MIGNOLO, Walter (2013). Histórias locais/projetos globais. Colonialidade, saberes subalternos e pensamento liminar. Belo Horizonte: Ed. UFMG, (Madrid). (2007). La idea de América Latina. La herida colonial y la opción decolonial. Barcelona: Gedisa.

MORETTI, C. Z.; STRECK, D. R (2013). Colonialidade e insurgência: contribuições para uma pedagogia latino-americana. Revista lusófona de educação, v. 24: 33-48.

PORTO-GONÇALVES, Carlos Walter (2015). Enciclopédia latinoamericana. disponível em <http://latinoamericana.wiki.br/@@verbetes> Acesso em: 15 de junho de 2021.

OLIVEIRA, Luiz Fernandes de; CANDAU, Vera Maria Ferrão (2010). Pedagogia decolonial e educação antirracista e intercultural no Brasil. Educ. rev. [online]. vol. 26, n.1: 15-40. ISSN 0102-4698. Disponível em: <http://dx.doi.org/10.1590/S0102-46982010000100002> Acesso em: 08 de março de 2019.

QUIJANO, Aníbal (2005). Colonialidade do poder, eurocentrismo e América Latina. In: LANDER, Edgardo. A colonialidade do saber, eurocentrismo e ciências sociais. Perspectivas Latino-americanas. Colección Sur Sur, CLACSO, Ciudad Autónoma de Buenos Aires. Argentina, setembro.

SANTOS, Antônio Bispo (2015). Colonização, Quilombos: modos e significações. Brasília.

SANTOS, Boaventura de Sousa (2010). Epistemologias del Sur. México: Siglo XXI.

TORRES, C. A (1996). A voz do biógrafo latino-americano: uma biografia intelectual. In: GADOTTI, M. (Org.). Paulo Freire: uma biobibliografia. São Paulo: Cortez: Instituto Paulo Freire; Brasília, DF: UNESCO.

WALSH, Catherine (2009). Interculturalidade, crítica e pedagogia decolonial: in-surgir, re-existir e reviver. In: CANDAU, Vera Maria (Org.). Educação intercultural na América Latina: entre concepções, tensões e propostas. Rio de Janeiro: 7 Letras.

ZAGO, Nadir (2008). Cursos pré-vestibulares populares: limites e perspectivas. Revista Perspectiva, Florianópolis, v. 26, n. 1: 149-174.

Artigo recebido em 20 de abril de 2021.

Artigo aprovado em 20 de junho de 2021.

DOI: $10.12957 /$ intellectus.2021.58444 